\title{
Quatro perguntas para Rubens R. R. Casara
}

\author{
Por Leonardo Rogério Miguel
}

Recebido em 26/11/2018

Aceito em 26/11/2018

Desde as "Marchas de 2013" às Eleições Presidenciais de 2018, passando pelo Impeachment de Dilma Rousseff e a prisão do ex-presidente Luiz Inácio Lula da Silva, "crise" é uma das palavras recorrentes na mídia e nas ruas. Esses eventos e suas impactantes consequências foram motivados como soluções para, assim declaradas, "crise política", crise de representatividade", "crise das instituições". Contudo, supostas soluções para crises surtem efeitos inesperados e, em muitos casos, podem alimentar profecias autorrealizáveis. Talvez, esta seja a condição daquilo que há, aproximadamente, dois anos é chamado de "crise do Estado Democrático de Direito". É a respeito dessa "crise", bem como de uma de suas narrativas, que trata o livro Estado Pós-democrático: neo-obscurantismo e gestão dos indesejáveis, do juiz de direito Rubens Roberto Rebello Casara. A bem da verdade, Casara declara não haver uma crise do Estado Democrático de Direito no país, mas uma manipulação do conceito e de uma narrativa sobre as recentes condições políticas e jurídicas nacionais para camuflar a situação real: o estado de exceção.

Rubens R. R. Casara é juiz de direito do Tribunal de Justiça do Rio de Janeiro. Professor no Programa de Pós-graduação Strictu Sensu em Saúde Pública da Escola Nacional de Saúde Pública Sergio Arouca/Fundação Oswaldo Cruz. O livro Estado Pós-democrático: neo-obscurantismo e gestão dos indesejáveis foi publicado pela editora Civilização Brasileira em 2017. Pela mesma editora, Casara publicou recentemente Sociedade sem Lei: pós-democracia, personalidade autoritária, idiotização e barbárie (2018)

Reinhart Koselleck (1923-2006) é um historiador alemão cujos trabalhos são fundamentais para os estudos e a compreensão do conceito de "Crise". Ao final de um texto exclusivamente dedicado àquele conceito, Koselleck diz:

\footnotetext{
O conceito de crise, que uma vez já teve o poder de propor alternativas inevitáveis, duras e inegociáveis, foi transformado para se ajustar às incertezas do que quer que pudesse ser favorecido em um dado momento. Tal tendência à vagueza e imprecisão, no entanto, pode ser vista como o sintoma de uma crise histórica que ainda não pode ser totalmente avaliada. Isso torna sobretudo importante para o acadêmico pesar cuidadosamente o conceito antes de adotá-lo em sua própria terminologia (Koselleck, R. "Crisis". In. Journal of the History of Ideas, Volume 67, N. 2, Abril de 2006. Pp. 399-400).
}

À luz dessas considerações, de que maneira o conceito de "crise" faz parte de sua atuação como Juiz de Direito do Tribunal de Justiça?

Casara: O significante "crise" perdeu o seu sentido original e tem sido utilizado como uma espécie de autorização para afastar os limites democráticos ao exercício do poder, de qualquer poder. A "vagueza e imprecisão", identificadas por Koselleck, são funcionais ao uso político do termo. Com Christian Laval e 
Pierre Dardot (2016), poderíamos falar em crise "como arma de guerra" ou, com Naomi Klein (2008), como elemento de uma "estratégia de choque", fundamental à imoderação típica do projeto neoliberal e ao crescimento do pensamento autoritário.

Não faltam exemplos de que conceito de crise tem sido manipulado para justificar a violação aos direitos e garantias fundamentais, bem como à própria democracia. Pense-se nas prisões fora das hipóteses legais justificadas a partir da afirmada crise na segurança pública. Os direitos fundamentais que, após a Segunda Guerra Mundial, passaram a ser pensados como limites intransponíveis ao arbítrio e à opressão, voltaram a ser relativizados pelo Poder Judiciário a partir do discurso da "crise", da necessidade de medidas excepcionais para momento excepcionais. O discurso da crise transforma uma garantia contra a opressão em um obstáculo à eficiência do Estado ou do mercado. A crise, que serve para alimentar novas crises em um espiral infinito, tornou-se uma positividade aos olhos daqueles que querem violar os limites constitucionais e democráticos.

Os membros do Poder Judiciário, por exemplo, que deveriam atuar como garantidores dos direitos fundamentais, a partir da evocação de um quadro de crise, sentem-se autorizados a relativizá-los ou simplesmente afastá-los. Em outras palavras, a "crise", definida de forma vaga e imprecisa, tornou-se uma desculpa para o arbítrio e a opressão. Tenho, como juiz de direito, procurado desvelar a funcionalidade antidemocrática que se esconde por de trás do discurso da crise e dos correlatos pedidos para relativizar direitos fundamentais. Cabe aos juízes comprometidos com a democracia, que buscam atuar no sentido de concretizar direitos e garantias fundamentais, identificar e desconstruir o discurso da "crise" no âmbito do Sistema de Justiça, isso porque a "crise" funciona não só como um modo de governar, mas também como uma desculpa para julgar contra a legalidade democrática.

Estado Pós-democrático: neo-obscurantismo e gestão dos indesejáveis nos chamou a atenção justamente pelos esclarecimentos a respeito do conceito de "crise" logo na introdução. Esse procedimento é necessário para dar sustentação a afirmações fortes de seu livro, como a hipótese de que, parafraseando o senhor, "não há verdadeira crise paradigmática do Estado Democrático de Direito" no Brasil. O que há de errado com o emprego da palavra "crise" nesse contexto? Como o fenômeno que o senhor denomina de "neo-obscurantismo" poderia ser articulado à "tendência à vagueza e à imprecisão" observada por Koselleck nos empregos do conceito de "crise"?

Casara: A palavra "crise", desde sua origem na Grécia, liga-se a um quadro provisório, um interregno em que algo pode, ou não, ser substituído. A palavra crise surge como um termo médico para retratar a situação em que o doente caminhava para a morte ou, a partir da própria doença, alcançava a cura. Na crise, o "novo" é possível, mas ainda não nasceu, ao mesmo tempo em que não se pode afirmar que o "velho" deixará de existir. Em outras palavras, a excepcionalidade e a provisoriedade são elementos do conceito de crise. É justamente a crença nessa excepcionalidade da crise que justifica a retórica que defende medidas excepcionais. O lema adotado pelo senso comum é o de que "para situações excepcionais são admitidas medidas excepcionais, enquanto durar a excepcionalidade".

Não me parece que exista uma verdadeira crise do Estado Democrático de Direito, forma jurídica que se caracteriza pela existência de limites rígidos ao exercício do poder, de qualquer poder. Hoje, embora muitos recorram ao discurso da "crise da democracia", que tem um efeito tranquilizador, pois manipula a esperança de que a democracia continua a existir e a crise um dia vai acabar, tenho sustentado que estamos diante de algo novo: o Estado Pós-Democrático, forma jurídica que resulta da racionalidade neoliberal e que se caracteriza tanto pela confusão entre poder político e poder econômico quanto pela imoderação e ausência de limites aos fins do mercado, em especial do mercado financeiro.

Me refiro ao neo-obscurantismo, que acompanha a pós-democracia, em razão de uma espécie de regressão pré-moderna, cujos exemplos são não só a já mencionada identificação entre os titulares do poder político e do poder econômico (vale lembrar de Berlusconi, Trump ou Dória), como também o novo prestígio das práticas inquisitoriais, em que as figuras do acusador e do julgador se confundem, e o modo de ver e atuar 
no mundo que trata tudo e todos como objetos. Por evidente, o neo-obscurantismo só se torna aceitável, e acaba naturalizado, a partir da manipulação do conceito de crise.

Ainda na introdução, encontramos a seguinte afirmação: “O que chamam de 'crise' é um modo de governar as pessoas". Isto nos faz lembrar de Dardot e Laval (2016) quando alegam que o neoliberalismo se tornou, para o Estado, uma alternativa de governabilidade. Como atua esse modo "crítico" de governar, especialmente em relação à "gestão dos indesejáveis"?

Casara: Novamente com Laval e Dardot, podemos falar de crise como uma arma política. Fala-se da crise, de variadas crises, como justificativa para medidas drásticas e, não raro, ilegais voltadas ao controle social dos indesejáveis, ou seja, daqueles que não interessam aos detentores do poder político e/ou econômico. Medidas que, muitas vezes, se dão no subterrâneo do sistema aparente de legalidade, como, por exemplo, as chacinas, as atuações de grupos paramilitares e outras formas de controle informal. Medidas que levam ao encarceramento em massa daqueles que não interessam ao projeto neoliberal, seja porque não dispõem de capacidade de produção ou consumo, aqueles que poderíamos chamar de pobres, alvos do que a criminologia crítica chama de criminalização da pobreza, por serem inimigos políticos da lógica neoliberal, ou seja, pessoas vistas como obstáculos à acumulação ilimitada e ao egoísmo que integram o projeto neoliberal.

O Brasil terá um novo presidente da República quando esta entrevista for publicada. Em um exercício de especulação, seja quem for o vencedor, quais seriam as chances de superarmos o Estado Pós-democrático? Como seria a narrativa de uma crise do próprio Estado Pós-democrático?

Casara: Para superar o Estado Pós-Democrático é importante reverter o processo de dessimbolização que transformou tudo e todos em mercadorias. A racionalidade neoliberal, que condiciona o atual estágio sem luvas do capitalismo, tende a destruir a civilização. Não por acaso, as pessoas passaram a naturalizar fenômenos como a tortura e relativizar os direitos fundamentais. Os limites civilizatórios ao arbítrio, cada dia mais, são desconsiderados.

A crise da pós-democracia exigiria uma ressimbolização que permitisse tanto a efetiva participação popular na tomada de decisões políticas quanto o respeito e a concretização dos direitos fundamentais, trunfos contra a opressão. Tenho trabalhado com a ideia de que é necessário construir uma nova subjetividade radicalmente comprometida com os direitos fundamentais. Os direitos fundamentais são o comum, aquilo que une todas as pessoas à civilização e impede o arbítrio, capaz de gerar uma nova racionalidade na qual a pessoa e a melhora da qualidade de vida de cada pessoa, pelo simples fato de ter nascido com vida, volte ser a preocupação e o objetivo de todas as ações. 